\title{
High-dose vitamin $C$ suppresses the invasion and metastasis of breast cancer cells via inhibiting epithelial-mesenchymal transition
}

This article was published in the following Dove Press journal: OncoTargets and Therapy

\author{
Ling-Hui Zeng' \\ Qing-Mei Wang ${ }^{1-3}$ \\ Lin-Yi Feng' \\ Yu-Dun $\mathrm{Ke}^{\prime}$ \\ Qian-Zi Xu' \\ An-Yi Wei ${ }^{\prime}$ \\ Chong Zhang (D') \\ Rong-Biao Ying $\mathbb{D}^{2}$ \\ 'Department of Pharmacology, Zhejiang \\ University City College, Hangzhou City, \\ Zhejiang Province 310015, People's \\ Republic of China; ${ }^{2}$ Department of \\ Surgical Oncology, Taizhou Cancer \\ Hospital, Wenling City, Zhejiang Province \\ 317500, People's Republic of China; \\ ${ }^{3}$ Department of Pharmacy, People's \\ Hospital of Zhengzhou, Zhengzhou City, \\ Henan Province 450053, People's \\ Republic of China
}

\begin{abstract}
Purpose: Vitamin C (VC) is a kind of essential nutrient in the body regarded as a canonical antioxidant during the past hundred years. However, the anti-cancer effect of VC is controversial. Our study is trying to clarify the relationship between VC dosage and breast cancer metastasis.
\end{abstract}

Methods: Human breast cancer cell lines Bcap37 and MDA-MB-453 were treated with VC at three different concentrations (low-dose, $0.01 \mathrm{mM}$; medium-dose, $0.1 \mathrm{mM}$; high-dose, $2 \mathrm{mM}$ ). Wound healing assays were conducted for migration assay; transwell tests were performed to detect the ability of cell invasion. The protein levels were evaluated by Western blot analysis or immunohistochemistry. Tumor xenografts in nude mice were built to test the effects of $\mathrm{VC}$ on breast cancer cell proliferation and metastasis.

Results: 0.01 and $0.1 \mathrm{mM}$ VC promoted cell migration and invasion when compared with the control group, but $2 \mathrm{mM}$ VC significantly suppressed cell migration and invasion of breast cancer cell lines. High-dose VC increased E-cadherin and reduced Vimentin, indicating that high-dose VC suppressed epithelial-mesenchymal transition (EMT) in breast cancer cells. Besides, high-dose VC inhibited cell invasion promoted by TGF- $\beta 1$ in breast cancer cells. Meanwhile, high-dose $\mathrm{VC}$ reversed the suppression of E-cadherin and enhancement of Vimentin induced by TGF- $\beta 1$ in breast cancer cells. Furthermore, high-dose VC significantly inhibited breast cancer metastasis in vivo.

Conclusion: High-dose VC inhibits cell migration and invasion of breast cancer cell lines through suppressing EMT. Thus, it may be considered as an anticancer drug candidate for breast cancer patients.

Keywords: vitamin C, metastasis, TGF- $\beta 1$, breast cancer

\section{Introduction}

The incidence of breast cancer accounts for $26.86 \%$ of the incidence of malignant tumors in China, ranking first among female malignant tumors. ${ }^{1,2}$ With the changes in the social and economic environment and many other factors, the incidence of breast cancer has increased rapidly in the world. ${ }^{3}$ Distant metastases are the leading cause of death among breast cancer patients. It is one of the critical challenges to suppress metastasis in breast cancer treatment. ${ }^{4}$ Breast cancer cells with stem cell properties are key contributors to cancer metastasis, resistance to chemotherapy, and radiation therapy. ${ }^{5,6}$ EMT, the process of transition from epithelial cells to mesenchymal-like cells, has been considered as the first step of initiating migration and metastasis. ${ }^{7}$ Some cells which experience EMT may lead to apoptosis, and the
Department of Pharmacology, Zhejiang

University City College, 50 Huzhou Road

Hangzhou City, Zhejiang Province

310015 , People's Republic of China

Tel +8657188016565

Fax +8657188018442

Email zhangchong@zucc.edu.cn

Rong-Biao Ying

Department of Surgical Oncology,

Taizhou Cancer Hospital, \#50 Zhenxin

Road, Wenling City, Zhejiang Province

317500, People's Republic of China

$\mathrm{Tel} / \mathrm{Fax}+8657686590019$

Email yingrongbiao@163.com 
process is called "Anoikis". ${ }^{8}$ However, some cancer cells may transfer epithelial cells with weak cell-cell adhesion and change to no cell-cell adhesion, ${ }^{9}$ and gain some characteristics similar to cancer stem cells. ${ }^{10,11}$ Multiple signaling pathways, such as STAT3 and mTOR, are involved in promoting the onset and development of cancer. ${ }^{12,13}$

$\mathrm{VC}$ was initially discovered between 16th to 18th centuries since many seamen died of scurvy owing to the deficiency of fruits and vegetables. ${ }^{14}$ As a kind of nutrition, $\mathrm{VC}$ is thought as an essential cofactor in eight kinds of enzymes thus far. ${ }^{15}$ Therefore, VC becomes a hot topic in other aspects such as immune system, oxidative damage, and anticancer function. In the early 1970s, an American chemist Linus Pauling, the laureate with two-time Nobel Prize and a Scottish surgeon Ewan Cameron reported that supplement VC in terminal human cancer patients could prolong their lives. ${ }^{16,17}$ However, some researches proposed almost simultaneously the failure of high-dose supplemental of $\mathrm{VC}$ on rescuing advanced cancer patients. ${ }^{18}$ Thus, the anti-cancer effect of VC is controversial, and the main difference between them is the method of administration. In this study, we investigated the anti-cancer effect of $\mathrm{VC}$ at different concentrations in breast cancer cells to mimic the concentrations of $\mathrm{VC}$ in plasma by various administration. Furthermore, it was reported that VC dramatically impaired tumor growth and eradicated liver cancer stem cells. ${ }^{19}$ Thus, we hypothesized that VC might be a potential anti-metastasis drug in cancer treatment.

\section{Materials and methods Materials}

VC was purchased from Aladdin Industrial Corporation (Shanghai, China). VC was stored at $4{ }^{\circ} \mathrm{C}$ and dissolved in RPMI-1640 (Hyclone, USA), and the $\mathrm{pH}$ was adjusted to 7.0 using $10 \mathrm{M}$ sodium hydroxide. TGF- $\beta 1$ was purchased from PeproTech (Rocky Hill, NJ, USA).

\section{Cell culture}

Breast cancer cell lines Bcap37 and MDA-MB-453 were purchased from the Shanghai Institute of Biochemistry and Cell Biology (Shanghai, China). Cells were cultured in RPMI-1640 (Hyclone, Logan, UT, USA) plus 10\% fetal bovine serum (FBS, Bovogen, Australia) as well as $100 \mathrm{U} /$ $\mathrm{mL}$ of penicillin/streptomycin (Gibco, Gaithersburg, $\mathrm{MD}$, USA) and maintained under humidified conditions $\left(37^{\circ} \mathrm{C}\right.$, $5 \% \mathrm{CO}_{2}$ ).

\section{Wound healing assay}

Cells suspension containing $1 \times 10^{6} / \mathrm{mL}$ cells were seeded on a 24-well plate (Corning, NY, USA), then a wound was made by a sterile $200-\mu \mathrm{L}$ pipette tip when the cells in each well reached to $100 \%$ confluence. Cells were washed with PBS until there were no floating cells on the scratch and supplied medium with $10 \%$ FBS containing various concentrations of VC. Cells were fixed with pre-cooling $4 \%$ formaldehyde and stained with crystal violet for $30 \mathrm{~min}$. Images were captured by Nikon-TS100 microscope (Nikon, Tokyo, Japan). In addition, the average width of each scratch was analyzed by the Image J software.

\section{Cell invasion assay}

Cells were cultured with medium without FBS for $12 \mathrm{~h}$, all the cells were collected by FBS-free medium, and the suspension $(200 \mu \mathrm{L})$ containing $1 \times 10^{5}$ cells were seeded onto the upper chamber of 24-well transwell plate (poresize, $8.0 \mu \mathrm{m}$, Corning, USA). The lower chamber was supplemented medium with $10 \%$ FBS containing various concentrations of VC. The polycarbonate filter in the bottom of the upper chamber was removed. Then it was fixed and stained with crystal violet for $30 \mathrm{~min}$. The cells passing through the filter were randomly selected and captured by Nikon-TS100 microscope. Lastly, the average cell number in each well was counted with by image $J$ software.

\section{Western blot analysis}

Bcap37 and MDA-MB-453 cells were treated with VC for $48 \mathrm{~h}$. The total protein of cells was extracted with Cell Extraction Buffer (BioSource, Camarillo, CA). The protocol of Western blot was performed as reported before.$^{20}$ Briefly, the proteins were separated by sodium dodecyl sulfate-polyacrylamide gel electrophoresis (SDS-PAGE) and transferred to PVDF membrane; the membranes were blocked with 5\% skim milk. After rinsing gently with PBS, the membranes were incubated with primary antibodies E-cadherin (1:1000; Cell Signaling Technology, Beverly, MA, USA), Vimentin (1:1000; Santa Cruz Biotechnology, CA, USA), followed by second antibody Anti-rabbit IgG (H+L) (DyLight ${ }^{\mathrm{TM}} 8004 \mathrm{X}$ PEG Conjugate) (1:100,000; Cell Signaling Technology) or Anti-mouse $\operatorname{IgG} \quad(\mathrm{H}+\mathrm{L}) \quad$ (DyLight ${ }^{\mathrm{TM}} 680$ Conjugate) (1:100,000; Cell Signaling Technology) according to sources of species. Subsequently, the strength of fluorochrome was captured by the Odyssey CLx Infrared Imaging System (LICOR Biosciences, NE, USA). Then, the membranes were incubated with GAPDH antibody (1:1500; Cell Signaling 
Technology), and the next operations were the same as described above.

\section{Immunohistochemical analysis}

Fresh tumors were fixed with $10 \%$ neutral formalin for one week and then embedded in paraffin. The tissues were sectioned at a thickness of $4 \mu \mathrm{m}$. Immunohistochemistry staining for Vimentin was incubated at $4{ }^{\circ} \mathrm{C}$ overnight and then HRP-labeled secondary antibody for two hours. The 3,3-diaminobenzidine (DAB) solution was used for the development of brown color to identify the expression of Vimentin and E-cadherin, respectively.

\section{Hematoxylin and eosin (H\&E) staining}

Samples were prepared as immunohistochemistry. Four $\mu \mathrm{m}$ tissue samples were performed by using the Histostain-Plus Kit (Kangwei Reagents, Beijing, China). Tissues were stained with hematoxylin for the proper time, then rinsed samples for eosin staining. Neutral balsam was used to preserve samples.

\section{Tumor xenografts in nude mice}

Three-month-old female nude mice were purchased from Shanghai SLAC Laboratory Animal Corporation. All mice were housed at Zhejiang University Animal Care Facility, and all animal experiment operations were conducted in keeping with guidelines approved by Zhejiang University Institutional Animal Care and Use Committee, with ethical approval number 16172. Human breast cancer Bcap37 xenografts were established by injecting $1 \times 10^{6}$ cells subcutaneously into nude mice. A week later, the mice were grouped and treated with $\mathrm{VC}$ when the tumor reached a volume of 50 to $150 \mathrm{~mm}^{3}$. Tumor-bearing mice were both divided into two groups, and each group included five mice. Besides, $1 \times 10^{6}$ cells (100 $\mu \mathrm{L}$ PBS suspension) were injected into the tail vein of nude mice to detect lung metastasis. The mice were treated with normal saline or $\mathrm{VC}(4 \mathrm{~g} / \mathrm{kg})$ through intraperitoneal injection. In the following 24 days, body weight changes of tumor-bearing mice were detected every three days. Tumor weights and lung metastases were assessed after the mice were sacrificed.

\section{Statistics}

All quantitative analysis was performed using SPSS 13.0 J software (SPSS, Inc., Chicago, IL, USA) and expressed as mean \pm SEM. Two-tailed student's t-tests were used to examine the significance of differences two groups. Before applying ANOVA, we made sure that the dependent variable was approximately normally distributed, and then one-way analysis of variance (ANOVA) with Tukey's multiple comparisons posttests were used to determine the significance of differences between multiple groups. A value of $p<0.05$ was defined as statistical significance.

\section{Results \\ Different concentrations of VC demonstrated opposite effects on the migration and invasion of breast cancer cells}

Firstly, we determined whether VC could affect the migration and invasion of breast cells. Figure 1 showed scratch pitch of cells treated with VC $(2 \mathrm{mM})$ was more extensive than the control group, indicating that high-dose $\mathrm{VC}$ had a robust inhibition effect on the migration of breast cancer cells. Also, the invasion assay showed that the number of cells went through the membrane was significantly inhibited in $2 \mathrm{mM} \mathrm{VC}$ treatment group, compared with the control group (Figure 2).

Interestingly, $0.1 \mathrm{mM} \mathrm{VC}$ had a significant effect on promoting migration and invasion when compared with the control group in breast cancer cells (Figures 1B, C and 2B, C). Thus, these results indicated that high-dose $\mathrm{VC}$ suppressed the migration and invasion ability of breast cancer cells, but lowdose VC had opposite effects. In summary, the dose of VC should be precisely controlled when it comes to the studies and treatment of migration and invasion of breast cancer cells.

\section{Different doses of VC affected EMT in breast cancer cells}

In order to investigate the possible mechanisms of $\mathrm{VC}$ on the migration and invasion of breast cancer cells, we treated both Bcap37 and MDA-MB-453 cells with different dosages of VC to detect EMT related markers, including an epithelial marker E-cadherin and a mesenchymal marker Vimentin. We found the expressions of E-cadherin were reduced and Vimentin were increased in $0.1 \mathrm{mM} \mathrm{VC}$ group, compared with the control group (Figure 3). However, the two proteins showed an inverse proportion at high-dose $\mathrm{VC}$ group, $2 \mathrm{mM}$ $\mathrm{VC}$ increased E-cadherin and reduced Vimentin in both Bcap37 and MDA-MB-453 cells.

\section{High-dose VC rescued the EMT induced by TGF- $\beta$ I}

We have found that high-dose VC can inhibit EMT in breast cancer cells. In order to investigate whether high-dose $\mathrm{VC}$ 


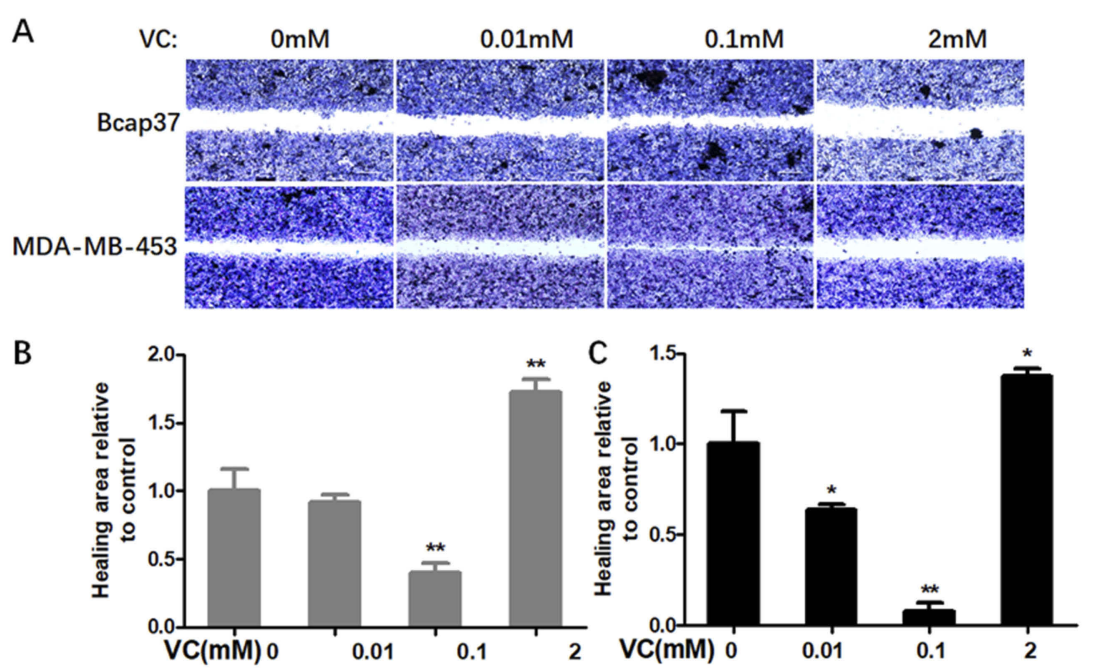

Figure I The effect of VC on the migration of breast cancer cells. (A) Breast cancer cells were gently scratched with a sterile pipette tip, washed with PBS three times, incubated with the indicated concentrations of VC for $24 \mathrm{~h}$. Photographs were taken under a microscope; scale bar $=20 \mu \mathrm{m}$. (B) Quantitative analysis of scratch pitch in Bcap37 cells. (C) Quantitative analysis of scratch pitch in MDA-MB-453 cells. ${ }^{*} p<0.05$ and $*^{*} p<0.01$, as compared to the group without VC treatment.

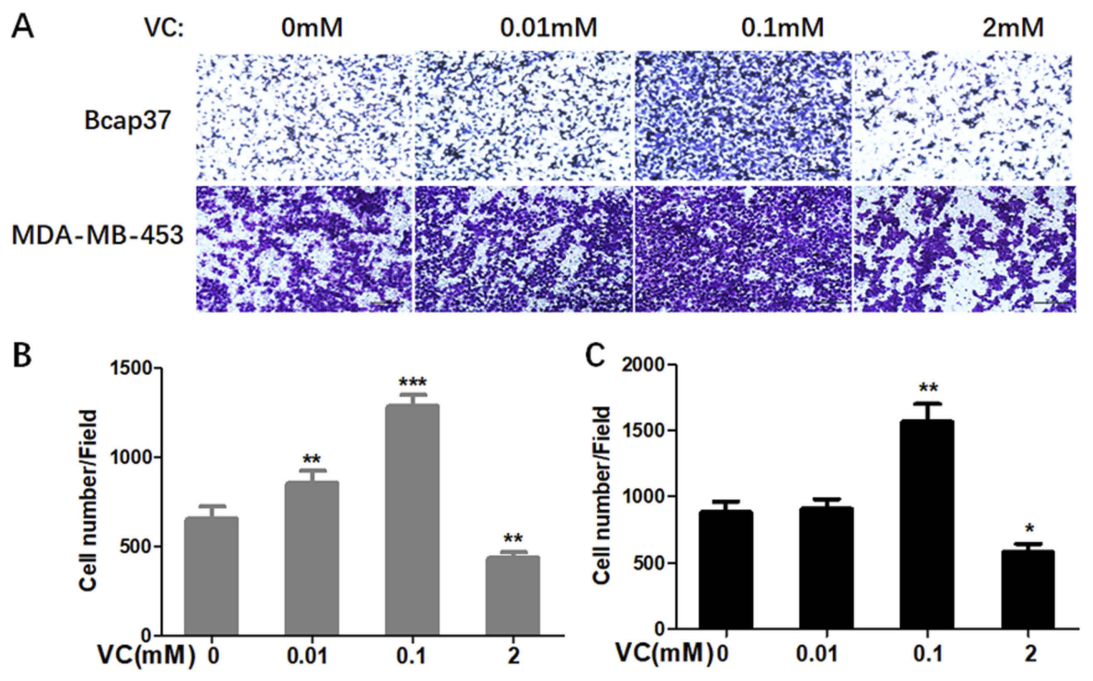

Figure 2 The effect of VC on the invasion of breast cancer cells. (A) Breast cancer cells were seeded in the upper chamber, and then cells were incubated with 0.01 mM, $0.1 \mathrm{mM}, 2 \mathrm{mM}$ VC for $24 \mathrm{~h}$. Cancer cells invaded the underside of the membrane were fixed in I\% methanol and stained by crystal violet. Quantification of invaded Bcap 37 (B) and MDA-MB-453 (C) cells were counted in transwell invasion assays. ${ }^{*} p<0.05,{ }^{*} p<0.01$ and $*^{* * *} p<0.00 \mathrm{I}$, as compared to no VC group.

could suppress TGF- $\beta 1$-induced EMT in breast cancer cells, we treated breast cancer cells with different dosages of TGF- $\beta 1$ to build a proper EMT induction model. We found that TGF- $\beta 1$ inhibited the expression of E-cadherin, but activated vimentin in a dose-dependent manner in Bcap37 and MDA-MB-453 cells (Figure 4A-C). Therefore, $10 \mathrm{ng} / \mathrm{mL}$ TGF- $\beta 1$ was chosen to induce EMT in our study. As shown in Figure 4D-F, 2 mM VC reversed the suppression of E-cadherin and enhancement of Vimentin induced by $10 \mathrm{ng} / \mathrm{mL}$ TGF- $\beta 1$ in Bcap37 cells, indicating that high-dose VC could rescue TGF- $\beta 1$ induced
EMT. Similar results were also observed in MDA-MB-453 cells (Figure 4G-I).

\section{High-dose VC inhibited TGF- $\beta$ I promoted cell migration and invasion}

Next, we performed wound healing assay and transwell assay to test the efficiency of $\mathrm{VC}$ on rescuing TGF- $\beta 1$ induced EMT. From the view of wound distance, we verified that high-dose VC inhibited cell migration in Bcap37 and MDA-MB- 453 cells, TGF- $\beta 1$ promoted cell migration, and TGF- $\beta 1$ plus VC showed smaller wound space when 


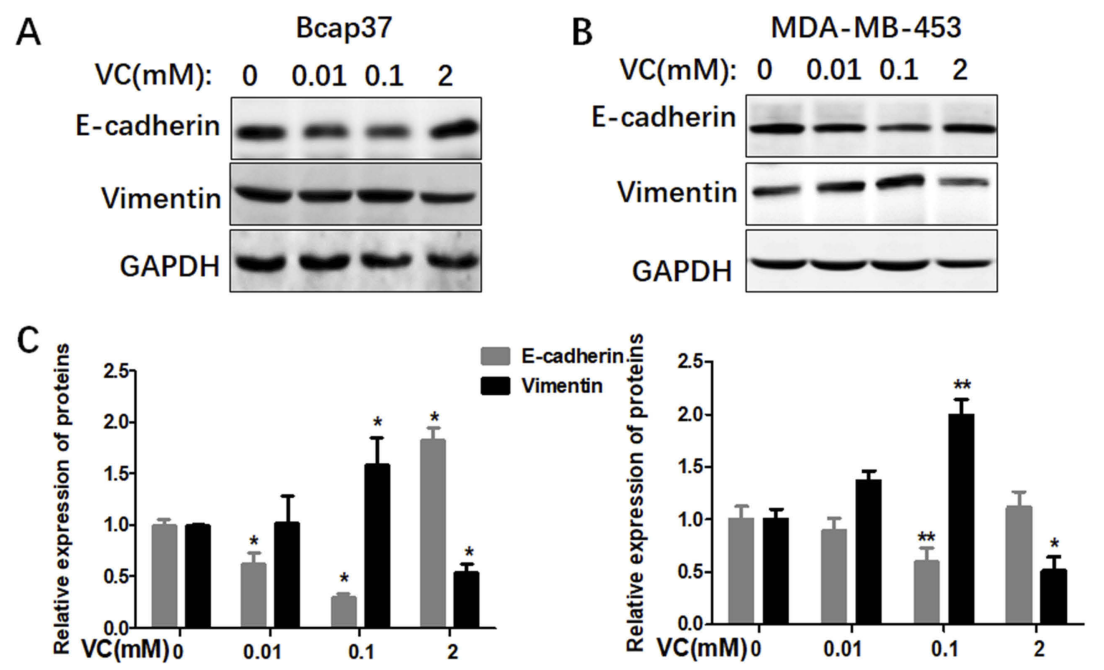

Figure 3 Different doses of VC affected EMT in breast cancer cells. (A and B) Different doses of VC affected the expression of E-cadherin and Vimentin in Bcap37 and MDA-MB-453 cells. (C) Statistical analysis for the expression of E-cadherin and Vimentin in breast cancer cells.

compared with TGF- $\beta 1$ treated alone (Figure 5). In addition, high-dose VC also inhibited TGF- $\beta 1$ promoted invasion in Bcap37 and MDA-MB-453 cells (Figure 6).

\section{High-dose VC inhibited the proliferation and metastasis of breast cancer cells}

As high-dose VC inhibited the metastasis of breast cancer cells in vitro, we were curious whether VC could suppress the metastasis of breast cancer cells in vivo. VC treated mice showed no significant body weight loss on day 24 compared with the control group (data not shown). Bcap37 cells could easily metastasize to the lungs in the control group, but lung metastasis of Bcap37 cells was significantly suppressed in high-dose of VC group compared with the control group (Figure 7A), and immunohistochemical analysis showed that $\mathrm{VC}$ reduced the expression of Vimentin in breast cancer cells (Figure 7B), and the number of lung metastatic foci in each mouse was dramatically decreased in VC-treated group (Figure 7C). The evidence indicated that high-dose VC inhibited the proliferation and metastasis of breast cancer cells in vivo.

\section{Discussion}

VC is a water-soluble micronutrient essential for human health. The ingestion of citrus fruits is crucial for primates, even including human for the lack of gluconolactone oxidase (Gulo) during evolution. ${ }^{21,22}$ Gulo-/- mice, which have lost the capacity of synthesizing $\mathrm{VC}$, must depend on dietary $\mathrm{VC}$ intake like a human. $0.33 \mathrm{~g} / \mathrm{L}$ is the minimum dietary amount for the maintenance of Gulo-/- mice, and the corresponding concentration of $\mathrm{VC}$ in the blood is $24.88 \mu \mathrm{M}$. When the supplement add up to $3.3 \mathrm{~g} / \mathrm{L}$, the level of VC increases to $80.9 \mu \mathrm{M}$, similar to C57BL/6J mice $(88.41 \mu \mathrm{M}) .^{23}$ It is hard to increase the concentration of $\mathrm{VC}$ in plasma and tissue owing to the limitation of bioavailability. $^{24,25}$ However, intravenous VC can exceed $1200 \mu \mathrm{M}$ and make some progress on earlier cancer researches. ${ }^{26}$ Furthermore, combining high-dose VC (1.25 to $20 \mathrm{mM}$ ) with conventional anti-cancer drugs can have therapeutic advantages against breast cancer cells. ${ }^{27}$ However, the relationship between VC dosage and breast cancer metastasis has not been clarified. Thus, we set three doses of VC $(0.01 \mathrm{mM}, 0.1 \mathrm{mM}$, and $1 \mathrm{mM})$ to mimic the different VC concentrations in plasma via various administration, and the objective of the present study was to evaluate the effects of three doses of VC on breast cancer metastasis. In our study, we have demonstrated that highdose VC suppressed the migration and invasion ability of breast cancer cells, but low-dose of VC had opposite effects. Furthermore, high-dose VC significantly inhibited breast cancer metastasis in vivo. Thus, VC showed promise to become an effective anticarcinogen when the concentration was control reasonably in breast cancer treatment, and more remarkable, the concentration of $\mathrm{VC}$ played a vital role in deciding VC act as cancer-promotion or cancerinhibition.

EMT, the process of epithelial to mesenchymal transition, was initially studied under embryonic morphogenesis. ${ }^{28}$ In addition, EMT process plays an essential role in a variety of 

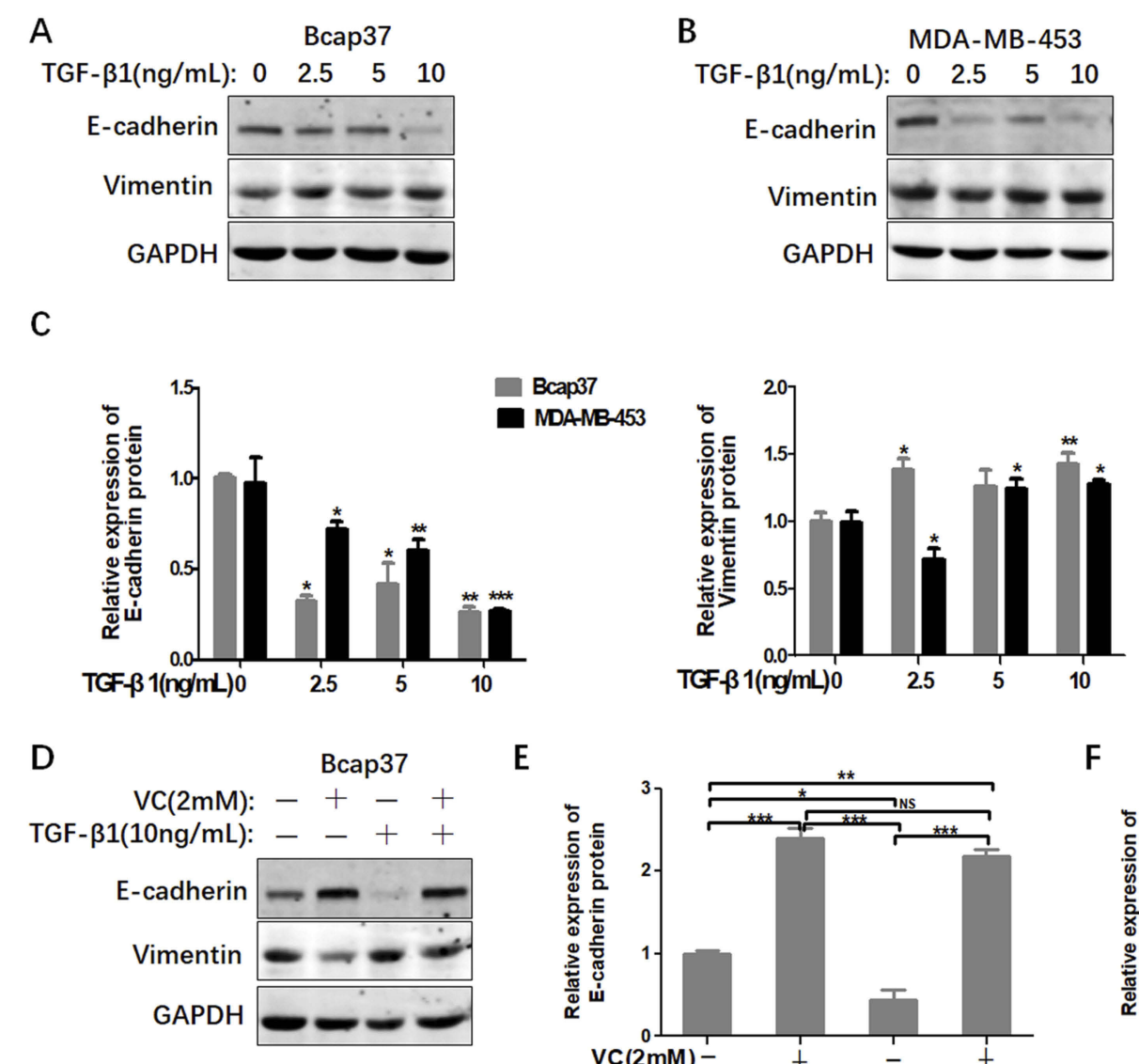

E
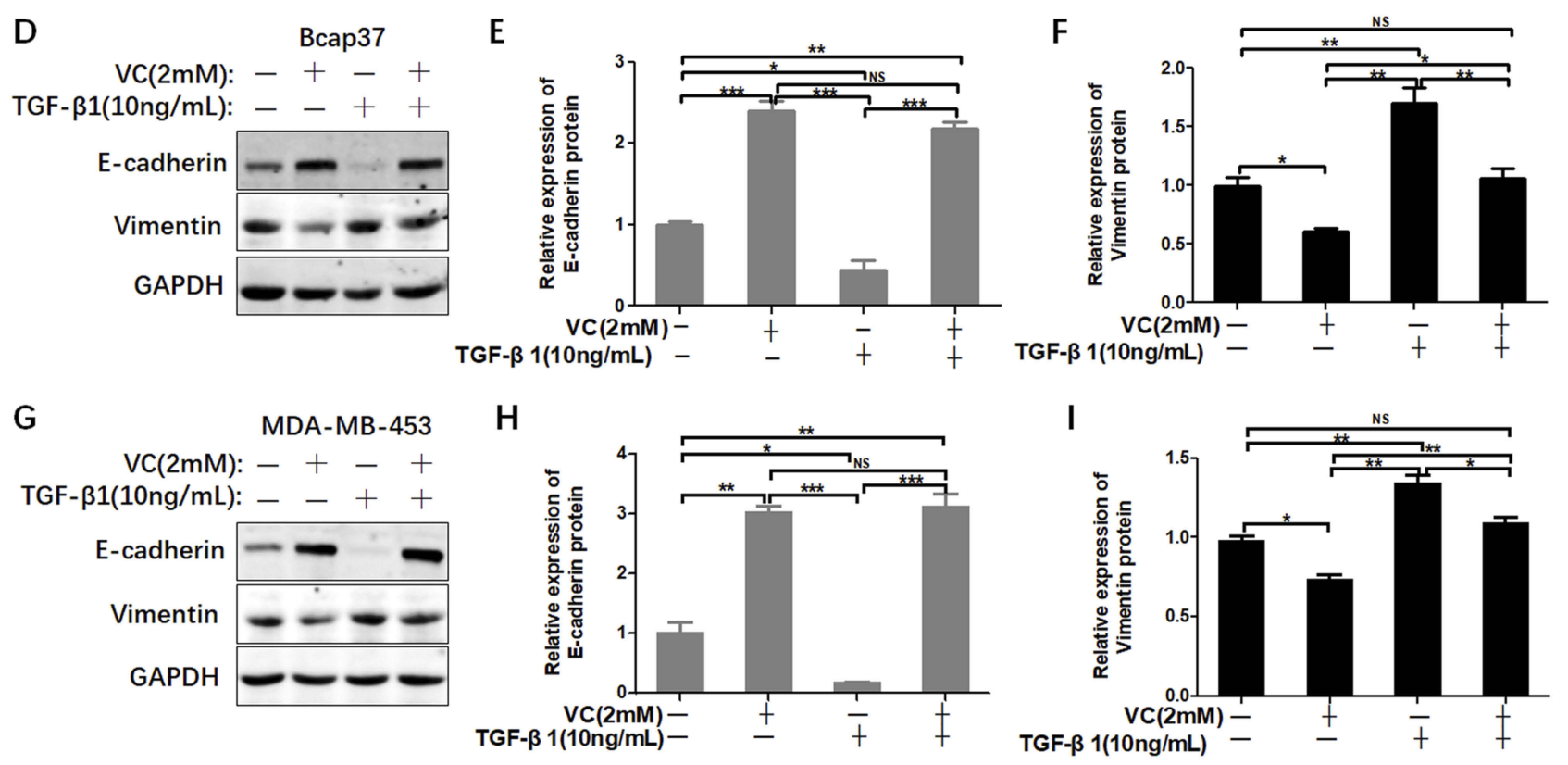

Figure 4 High-dose VC rescued TGF- $\boldsymbol{\beta}$ I induced EMT in breast cancer cells. (A and B) TGF- $\boldsymbol{\beta}$ I increased the level of E-cadherin and inhibited the expression of Vimentin in Bcap37 and MDA-MB-453 cells. (C) Statistical analysis for the expression of E-cadherin and Vimentin. (D) 2 mM VC rescued the EMT induced by TGF- $\boldsymbol{\beta}$ I in Bcap37 cells. (E and $\mathbf{F}$ ) Statistical analysis of E-cadherin and Vimentin expression in Bcap37 cells. (G) 2 mM VC rescued the EMT induced by TGF- $\boldsymbol{\beta} \mid$ in MDA-MB-453 cells. (H and $\mathbf{I})$ Statistical analysis of E-cadherin and Vimentin expression in MDA-MB-453 cells. $* p<0.05, * * p<0.01$ and $* * * p<0.001$.

pathological processes such as wound healing and tumor metastasis. ${ }^{29,30}$ E-cadherin, a kind of adhesion protein, is proved to be repressed in cancer cells. ${ }^{31,32}$ A certain amount of adhesion protein E-cadherin is crucial for maintaining epithelial cells' traits. Once cells lose the adhesion among them, they become free for motivation and gain some properties similar to CSCs such as CSC-like markers and enhance tumor formation rate in animal models. ${ }^{33-35}$ Vimentin is a widely used marker of the mesenchymal phenotype and regulates cell migration in many cancer cell types, and many aggressive breast cancer cell lines overexpress vimentin. ${ }^{36}$ The key signaling pathway involved inducing EMT is the TGF- $\beta$. TGF- $\beta 1$, a kind of multifunctional cytokine, was reported to stimulate the PI3K/Akt signaling pathway and the downstream mTOR/S6K signaling pathway. ${ }^{37}$ In our study, we found that high-dose VC increased E-cadherin and reduced Vimentin in breast cancer cells, but low-dose of $\mathrm{VC}$ had opposite effects. Also, high-dose VC inhibited cell invasion promoted by TGF- $\beta 1$ in breast cancer cells. Meanwhile, high-dose VC reversed the suppression of E-cadherin and 


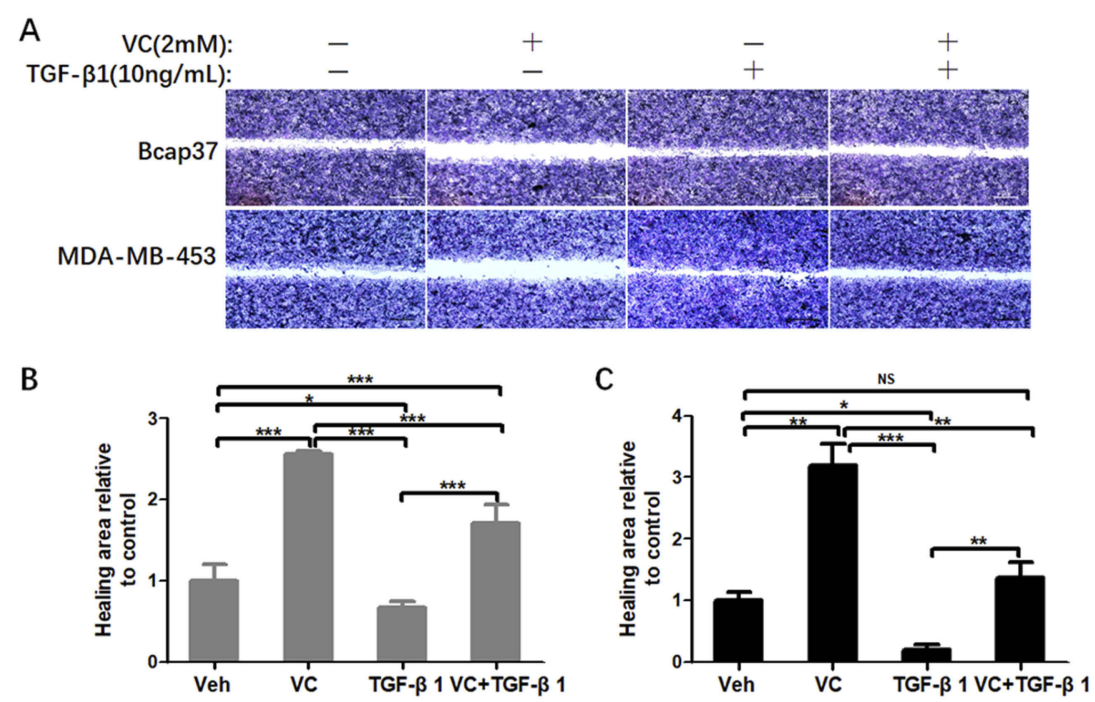

Figure 5 High-dose VC inhibited cell migration induced by TGF- $\beta$ I in breast cancer cells. (A) Representative images were taken from the wound distance after incubation for $24 \mathrm{~h}$ in Bcap37 and MDA-MB-453 cells. Scale bar $=20 \mu \mathrm{m}$. (B) Quantification of wound distance in Bcap37 cells. (C) Quantification of wound distance in MDA-MB-453 cells. ${ }^{*} p<0.05 ; * p<0.01 ; * * * p<0.001$.

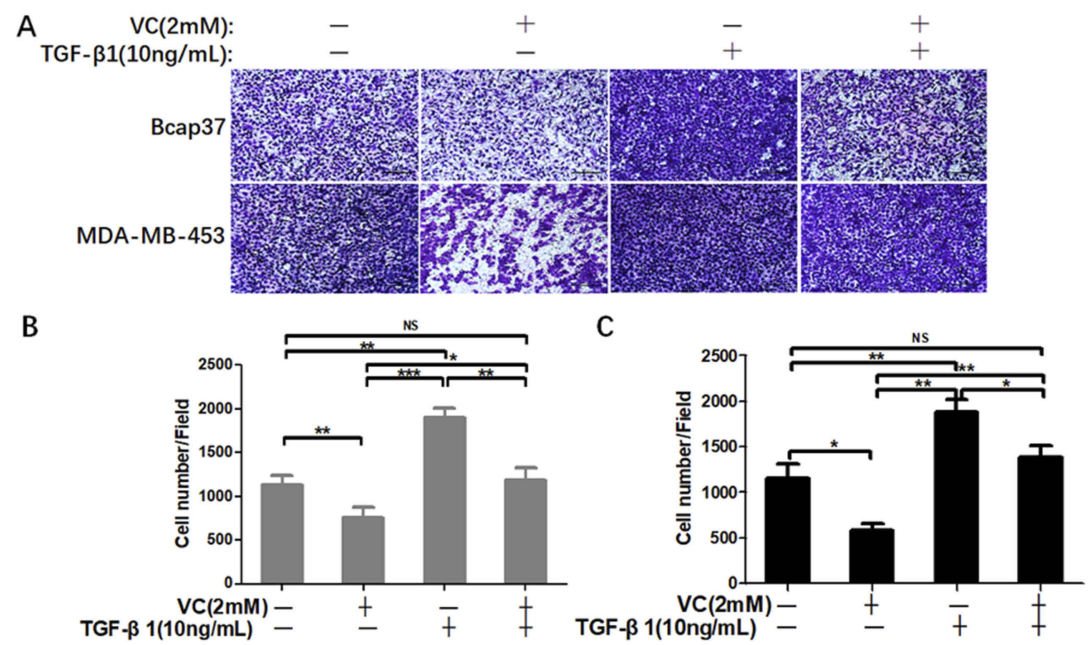

Figure 6 High-dose VC inhibited cell invasion promoted by TGF- $\beta$ I in breast cancer cells. (A) Breast cancer cells were seeded in the upper chamber, and then cells were incubated with $2 \mathrm{mM}$ VC and/or $10 \mathrm{ng} / \mathrm{mL}$ TGF- $\beta$ I for $24 \mathrm{~h}$. Cancer cells invaded the underside of the membrane were fixed in $1 \%$ methanol and stained by crystal violet. Quantification of invaded Bcap37 (B) and MDA-MB-453 (C) cells were counted in transwell invasion assays. ${ }^{*} p<0.05$, $* * p<0.01$ and $* * * p<0.00 \mathrm{I}$.

enhancement of Vimentin induced by TGF- $\beta 1$ in breast cancer cells. These results indicated that high-dose VC could suppress TGF- $\beta 1$ induced EMT in breast cancer cells.

As for the difference of sensitive between cancer cells and normal cells under pharmacological $\mathrm{VC}$ treatment, there are many studies about potential mechanisms such as the formation of $\mathrm{H}_{2} \mathrm{O}_{2},{ }^{38}$ depletion of cellular ATP levels, ${ }^{39}$ and oxidative stress damaged DNA. ${ }^{40}$ Understanding the mechanism of selective killing ability of $\mathrm{VC}$ gives a better guide for cancer patients who benefit from pharmacologic ascorbate therapy. In our study, VC suppresses the proliferation of breast cancer cell than that in normal cells (Supplementary Figure 1A). Two mM $\mathrm{VC}$ has pro-oxidative properties and causes cytotoxicity of breast cancer cells by selective oxidative stress, ${ }^{41}$ and Sodium vitamin $\mathrm{C}$ transporter 2 (SVCT2) plays a crucial role in transporting VC. ${ }^{42}$ We found that the levels of SVCT2 in tumor samples from breast cancer patients were lower than normal tissues (Supplementary Figure 1B). Thus, we hypothesized normal cells could transport more VC to eliminate the cytotoxicity of high-dose $\mathrm{VC}$ than breast cancer cells via overexpressing SVCT2. However, further investigation is needed to verify the hypothesis. 

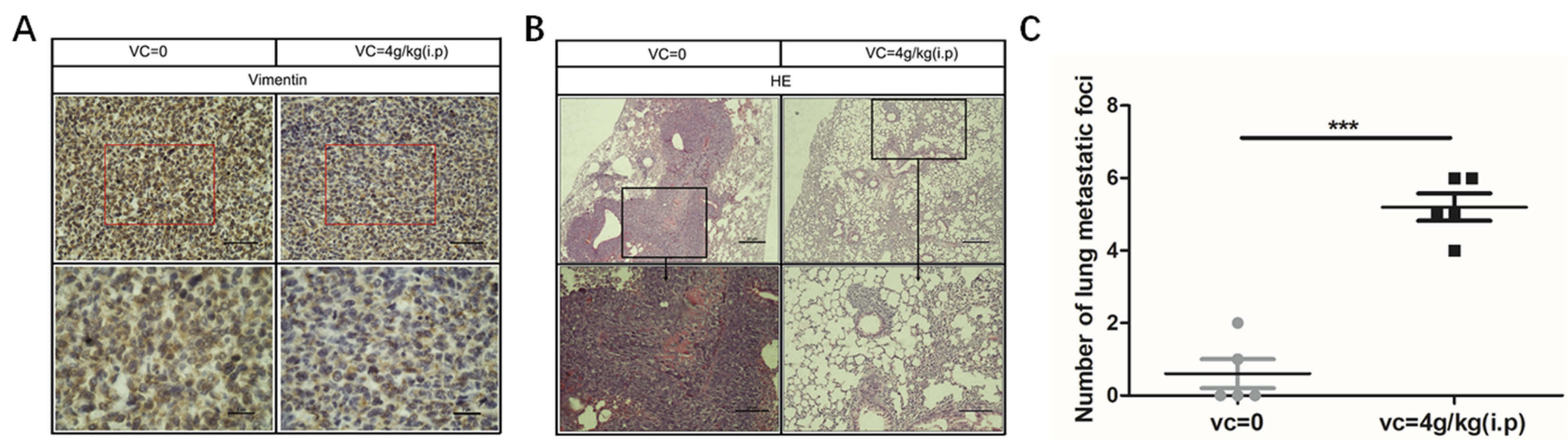

Figure 7 High-dose VC inhibited the metastasis of breast cancer cells. (A) Immunohistochemical analysis showed that VC reduced the expression of Vimentin. (B) H\&E staining showed VC reduced lung metastases. (C) Lung metastatic foci were counted. $* * * p<0.001$.

\section{Conclusion}

VC intravenous has been widely used to treat cancer patients in American. Researchers all over the world have made significant progress about VC despite statistically undetectable gaps. Undoubtedly, numerous successes in clinical practice made it worthy of investigating the effect of VC in cancer treatment. However, to figure out the more accurate dosage in different patients and clarify the molecular mechanisms of VC in treating cancer will be our next tasks even we have known the correlation between $\mathrm{VC}$ and some hypotheses such as CSC, EMT. Above all, the finding of precise and pivotal molecular will promote $\mathrm{VC}$, the safe and cheap nutriment, to benefit more cancer patients.

\section{Abbreviations}

VC, vitamin C; EMT, epithelial-mesenchymal transition; H\&E, Hematoxylin and eosin; Gulo, gluconolactone oxidase; SVCT2, Sodium vitamin C transporter 2; SDS-PAGE, sodium dodecyl sulfate-polyacrylamide gel electrophoresis; DAB, 3,3-diaminobenzidine.

\section{Acknowledgment}

This work was supported by the Teachers Research Fund of Zhejiang University City College (J-19006) and Scientific and Technological Developing Scheme of Hangzhou City (20191203B49).

\section{Disclosure}

The authors report no conflicts of interest in this work.

\section{References}

1. Chen W, Zheng R, Baade PD, et al. Cancer statistics in China, 2015. CA Cancer J Clin. 2016;66(2):115-132. doi:10.3322/caac.21338
2. Bray F, Jemal A, Grey N, Ferlay J, Forman D. Global cancer transitions according to the Human Development Index (2008-2030): a population-based study. Lancet Oncol. 2012;13(8):790-801. doi:10.1016/S1470-2045(12)70211-5

3. Hao C, Wang Z, Gu Y, Jiang WG, Cheng S. Prognostic value of osteopontin splice variant-c expression in breast cancers: a meta-analysis. Biomed Res Int. 2016;2016:7310694. doi:10.1155/2016/7310694

4. Chuang HY, Lee E, Liu YT, Lee D, Ideker T. Network-based classification of breast cancer metastasis. Mol Syst Biol. 2007;3:140. doi: $10.1038 / \mathrm{msb} 4100180$

5. Sun Q, Lesperance J, Wettersten H, et al. Proapoptotic PUMA targets stem-like breast cancer cells to suppress metastasis. J Clin Invest. 2018;128(1):531-544. doi:10.1172/JCI93707

6. Korkaya H, Liu S, Wicha MS. Breast cancer stem cells, cytokine networks, and the tumor microenvironment. J Clin Invest. 2011;121 (10):3804-3809. doi:10.1172/JCI57099

7. Rhim AD, Mirek ET, Aiello NM, et al. EMT and dissemination precede pancreatic tumor formation. Cell. 2012;148(1-2):349-361. doi:10.1016/j.cell.2011.11.025

8. Grossmann J. Molecular mechanisms of "detachment-induced apoptosis-Anoikis". Apoptosis. 2002;7(3):247-260.

9. Jolly MK, Boareto M, Huang B, et al. Implications of the hybrid epithelial/mesenchymal phenotype in metastasis. Front Oncol. 2015;5:155. doi:10.3389/fonc.2015.00155

10. Polyak K, Weinberg RA. Transitions between epithelial and mesenchymal states: acquisition of malignant and stem cell traits. Nat Rev Cancer. 2009;9(4):265-273. doi:10.1038/nrc2620

11. Singh A, Settleman J. EMT, cancer stem cells and drug resistance: an emerging axis of evil in the war on cancer. Oncogene. 2010;29 (34):4741-4751. doi:10.1038/onc.2010.215

12. Amani H, Ajami M, Nasseri Maleki S, et al. Targeting signal transducers and activators of transcription (STAT) in human cancer by dietary polyphenolic antioxidants. Biochimie. 2017;142:63-79. doi:10.1016/j. biochi.2017.08.007

13. Amani H, Habibey R, Shokri F, et al. Selenium nanoparticles for targeted stroke therapy through modulation of inflammatory and metabolic signaling. Sci Rep. 2019;9(1):6044. doi:10.1038/s41598019-42633-9

14. Martini E. Jacques Cartier witnesses a treatment for scurvy. Vesalius. $2002 ; 8(1): 2-6$.

15. Levine M, Rumsey SC, Daruwala R, Park JB, Wang Y. Criteria and recommendations for vitamin C intake. JAMA. 1999;281(15):14151423. doi:10.1001/jama.281.15.1415

16. Cameron E, Pauling L. Supplemental ascorbate in the supportive treatment of cancer: reevaluation of prolongation of survival times in terminal human cancer. Proc Natl Acad Sci U S A. 1978;75 (9):4538-4542. doi:10.1073/pnas.75.9.4538 
17. Cameron E, Pauling L. Supplemental ascorbate in the supportive treatment of cancer: prolongation of survival times in terminal human cancer. Proc Natl Acad Sci U S A. 1976;73(10):3685-3689. doi:10.1073/pnas. 73.10 .3685

18. Creagan ET, Moertel CG, O'Fallon JR, et al. Failure of high-dose vitamin $\mathrm{C}$ (ascorbic acid) therapy to benefit patients with advanced cancer. A controlled trial. N Engl J Med. 1979;301(13):687-690. doi:10.1056/NEJM197909273011303

19. Lv H, Wang C, Fang T, et al. Vitamin C preferentially kills cancer stem cells in hepatocellular carcinoma via SVCT-2. NPJ Precis Oncol. 2018;2(1):1.

20. Zeng LH, Xu L, Rensing NR, Sinatra PM, Rothman SM, Wong M. Kainate seizures cause acute dendritic injury and actin depolymerization in vivo. $J$ Neurosci. 2007;27(43):11604-11613. doi:10.1523/ JNEUROSCI.0983-07.2007

21. Chaudhuri CR, Chatterjee IB. L-ascorbic acid synthesis in birds: phylogenetic trend. Science. 1969;164(3878):435-436. doi:10.1126/ science.164.3878.435

22. Chatterjee IB. Evolution and the biosynthesis of ascorbic acid. Science. 1973;182(4118):1271-1272. doi:10.1126/science.182.4118.1271

23. Kim $\mathrm{H}, \mathrm{Bae} \mathrm{S}, \mathrm{Yu} \mathrm{Y}$, et al. The analysis of vitamin $\mathrm{C}$ concentration in organs of gulo(-/-) mice upon vitamin $\mathrm{C}$ withdrawal. Immune Netw. 2012;12(1):18-26. doi:10.4110/in.2012.12.1.18

24. Graumlich JF, Ludden TM, Conry-Cantilena C, Cantilena LR Jr., Wang Y, Levine M. Pharmacokinetic model of ascorbic acid in healthy male volunteers during depletion and repletion. Pharm Res. 1997;14(9):1133-1139. doi:10.1023/a:1012186203165

25. Levine M, Conry-Cantilena C, Wang Y, et al. Vitamin C pharmacokinetics in healthy volunteers: evidence for a recommended dietary allowance. Proc Natl Acad Sci U S A. 1996;93(8):3704-3709. doi:10.1073/pnas.93.8.3704

26. Padayatty SJ, Levine M. Reevaluation of ascorbate in cancer treatment: emerging evidence, open minds and serendipity. J Am Coll Nutr. 2000;19(4):423-425.

27. Lee SJ, Jeong JH, Lee IH, et al. Effect of high-dose vitamin C combined with anti-cancer treatment on breast cancer cells. Anticancer Res. 2019;39(2):751-758. doi:10.21873/anticanres.13172

28. Shook D, Keller R. Mechanisms, mechanics and function of epithelial-mesenchymal transitions in early development. Mech Dev. 2003;120(11):1351-1383.

29. Kalluri R, Weinberg RA. The basics of epithelial-mesenchymal transition. J Clin Invest. 2009;119(6):1420-1428. doi:10.1172/JCI39104

30. Nieto MA, Huang RY, Jackson RA, Thiery JP. Emt: 2016. Cell. 2016;166(1):21-45. doi:10.1016/j.cell.2016.06.028

31. Mareel M, Vleminckx K, Vermeulen S, Bracke M, Van Roy F. Ecadherin expression: a counterbalance for cancer cell invasion. Bull Cancer. 1992;79(4):347-355.
32. Birchmeier W, Behrens J. Cadherin expression in carcinomas: role in the formation of cell junctions and the prevention of invasiveness. Biochim Biophys Acta. 1994;1198(1):11-26. doi:10.1016/0304-419x (94)90003-5

33. Mani SA, Guo W, Liao MJ, et al. The epithelial-mesenchymal transition generates cells with properties of stem cells. Cell. 2008;133 (4):704-715. doi:10.1016/j.cell.2008.03.027

34. Morel AP, Lievre M, Thomas C, Hinkal G, Ansieau S, Puisieux A. Generation of breast cancer stem cells through epithelial-mesenchymal transition. PLoS One. 2008;3(8):e2888. doi:10.1371/journal. pone.0002888

35. Chaffer CL, Brueckmann I, Scheel C, et al. Normal and neoplastic nonstem cells can spontaneously convert to a stem-like state. Proc Natl Acad Sci U S A. 2011;108(19):7950-7955. doi:10.1073/pnas.110 2454108

36. Vuoriluoto K, Haugen H, Kiviluoto S, et al. Vimentin regulates EMT induction by Slug and oncogenic H-Ras and migration by governing Axl expression in breast cancer. Oncogene. 2011;30(12):1436-1448. doi:10.1038/onc.2010.509

37. Bakin AV, Tomlinson AK, Bhowmick NA, Moses HL, Arteaga CL. Phosphatidylinositol 3-kinase function is required for transforming growth factor beta-mediated epithelial to mesenchymal transition and cell migration. J Biol Chem. 2000;275(47):36803-36810. doi:10.10 74/jbc.M005912200

38. Espey MG, Chen P, Chalmers B, et al. Pharmacologic ascorbate synergizes with gemcitabine in preclinical models of pancreatic cancer. Free Radic Biol Med. 2011;50(11):1610-1619. doi:10.1016/j. freeradbiomed.2011.03.007

39. Farah IO, Lewis VL, Ayensu WK, Mahmud O. Assessing the survival of MRC-5 and A549 cell lines upon exposure to ascorbic acid and sodium ascorbate. Biomed Sci Instrum. 2011;47:201206.

40. Ma Y, Chapman J, Levine M, Polireddy K, Drisko J, Chen Q. Highdose parenteral ascorbate enhanced chemosensitivity of ovarian cancer and reduced toxicity of chemotherapy. Sci Transl Med. 2014;6 (222):222ra218. doi:10.1126/scitranslmed.3007154

41. Bober P, Tomkova Z, Alexovic M, Ropovik I, Sabo J. The unfolded protein response controls endoplasmic reticulum stressinduced apoptosis of MCF-7 cells via a high dose of vitamin C treatment. Mol Biol Rep. 2019;46(1):1275-1284. doi:10.1007/ s11033-019-04598-w

42. Tian H, Ye X, Hou X, Yang X, Yang J, Wu C. SVCT2, a potential therapeutic target, protects against oxidative stress during ethanol-induced neurotoxicity via JNK/p38 MAPKs, NF-kappaB and miRNA125a-5p. Free Radic Biol Med. 2016;96:362-373. doi:10.1016/j.freeradbiomed. 2016.03.039
OncoTargets and Therapy

\section{Publish your work in this journal}

OncoTargets and Therapy is an international, peer-reviewed, open access journal focusing on the pathological basis of all cancers, potential targets for therapy and treatment protocols employed to improve the management of cancer patients. The journal also focuses on the impact of management programs and new therapeutic agents and protocols on patient perspectives such as quality of life, adherence and satisfaction. The manuscript management system is completely online and includes a very quick and fair peer-review system, which is all easy to use. Visit http://www.dovepress.com/ testimonials.php to read real quotes from published authors. 